\title{
Little-known Dangers to Natural History Collections: Bynesian Decay and Pyrite Decay
}

\author{
Rodrigo B Salvador ${ }^{\ddagger}$, Daniel C Cavallari§ \\ ‡ Museum of New Zealand Te Papa Tongarewa, Wellington, New Zealand \\ § Faculdade de Filosofia, Ciências e Letras de Ribeirão Preto, Ribeirão Preto, Brazil
}

Corresponding author: Rodrigo B Salvador (salvador.rodrigo.b@gmail.com)

Received: 26 May 2018| Published: 13 Jun 2018

Citation: Salvador R, Cavallari D (2018) Little-known Dangers to Natural History Collections: Bynesian Decay and Pyrite Decay. Biodiversity Information Science and Standards 2: e26983.

https://doi.org/10.3897/biss.2.26983

\section{Abstract}

The deterioration of specimens in natural history collections is a major concern of curators. Collections containing carbonatic specimens (e.g., molluscs, corals, fossils) are of special concern, since calcium carbonate $\left(\mathrm{CaCO}_{3}\right)$ can deteriorate in the presence of acidic vapours. There are two main types of danger related to these volatile acids, called Bynesian decay and pyrite decay.

In Bynesian decay, acetic and formic acids are released by storage materials (e.g., wood, varnishes, cardboard). If the collection is not under adequate conditions and presents high relative humidity and temperature, the acids react with the specimens' carbonate, yielding salts and carbon dioxide. The tell-tale "symptom" of an affected specimen is a thin white granular layer of efflorescing salts. Pyrite decay is somewhat similar, but restricted to fossils that contain the mineral pyrite $\left(\mathrm{FeS}_{2}\right)$. In high relative humidity, pyrite is oxidised, yielding sulfuric acid, which can in turn corrode carbonatic specimens lodged in the same drawer or cabinet.

The corrosion damage caused is irreversible, of course, but the affected specimens might be partially salvaged via specific cleaning and treating procedures. Nevertheless, it is better to just avoid the problem altogether by keeping the collection facilities in adequate conditions. It is hard to come up with a single solution for all the problems any given 
collection might face, but some measures are reasonably universal. First and foremost, one should strive to maintain a low relative humidity (45-50\%) and an appropriate temperature range $\left(16-21^{\circ} \mathrm{C}\right)$. This can be achieved, for instance, with HVAC systems and the use of common desiccant materials such as silica gel. Conditions within the collection should be monitored via the combined use of hygrometer, thermometer, and $\mathrm{pH}$ indicators. Furthermore, archival quality materials should be used as often as possible, such as steel drawers and cabinets with electrostatic coating, and acid-free paper and cardboard. Finally, specimens containing reactive pyrite must be kept isolated in archival quality plastic (e.g., mylar) or glass containers.

\section{Keywords}

acetic acid, calcium carbonate, formic acid, oxidation, sulfuric acid

\section{Presenting author}

Rodrigo B Salvador 